\title{
THE WEIGHT OF THE CRISIS: EVIDENCE FROM NEWBORNS IN ARGENTINA
}

\author{
Carlos Bozzoli and Climent Quintana-Domeque*
}

Abstract-We investigate how prenatal economic fluctuations affected birth weight in Argentina during the period from January 2000 to December 2005 and document its procyclicality. We find evidence that the birth weight of children born to low-educated (less than high school) mothers is sensitive to macroeconomic fluctuations during both the first and third trimesters of pregnancy, while those of high-educated (high school or above) mothers react only to the first trimester of pregnancy. Our results are consistent with low-educated women facing credit constraints and suffering from both nutritional deprivation and maternal stress, while high-educated women are affected only by stress.

\section{Introduction}

$\mathrm{T}$ HE analysis of how infant health responds to economic crises, or more generally macroeconomic shocks, has attracted considerable attention. During recessions, households may be prompted to reduce spending on items vital to children's health, including nutritious food and medical care for mothers and infants. Moreover, economic downturns are likely to worsen prenatal stress, increasing the risk of adverse birth outcomes, and may also cause public health services to deteriorate. However, evidence coming from developed countries shows that infant mortality actually decreases during recessions (Deheija \& Lleras-Muney, 2004). Results from developing country-level studies are more mixed (Cutler et al., 2002; Paxson \& Schady, 2005; Bhalotra, 2010).

As Miller and Urdinola (2010) recently emphasized, the variety of conclusions on the impact of macroeconomic shocks on children's health can be explained by the use of diverse methodologies or different behavioral responses to

Received for publication February 28, 2011. Revision accepted for publication January 29, 2013.

* Bozzoli: Universidad Torcuato Di Tella; Quintana-Domeque: University of Oxford and IZA.

We thank the editor (Alberto Abadie), two anonymous referees, Claudio Campanale, Matteo Cervellati, Jocelyn Finlay, Jed Friedman, Marco Gonzalez-Navarro, Carmen Herrero, Lawrence Katz, Vadym Lepetyuk, Catia Nicodemo, Sonia Oreffice, Emilia Simeonova, Fede Todeschini, ShinYi Wang, participants at the 7th Health Economics World Congress-IHEA (Beijing, July 2009), the FBBVA-IVIE Workshop Health and Macroeconomics (Madrid, December 2009), the 25th Annual Conference of the European Economic Association (Glasgow, August 2010), the 5th Annual Research Conference on Population, Reproductive Health, and Economic Development (Marseille, January 2011), the FEDEA Workshop on Health Economics (Madrid, December 2011), the Economic Circumstances and Child Health AEA-CSWEP session (Chicago, January 2012), the 17th Annual Meetings of the Society of Labor Economists (Chicago, May 2012), the 26th Annual Conference of the European Society for Population Economics (Bern, June 2012), and the 27th Annual Conference of the European Economic Association (Málaga, August 2012) for helpful comments and suggestions. We also thank the DEIS (Dirección de Estadísticas e Información en Salud) of Ministerio de Salud de Argentina and the CIF (Centro de Investigación en Finanzas) of Universidad Torcuato Di Tella, and especially Guido Sandleris, Ernesto Schargrodsky, and Julieta Serna for providing us access to disaggregate consumer confidence indicators. The usual disclaimers apply. C.Q.-D. acknowledges financial support from the Spanish Ministry of Science and Innovation (ECO 2011-29751).

A supplemental appendix is available online at http://www.mitpress journals.org/doi/suppl/10.1162/REST_a_00398. distinct macroeconomic shocks. Households may be able to smooth consumption or at least buffer expenditures on goods that protect health as long as they are not credit constrained, which may explain why the mortality of children born to less educated women is more sensitive to economic shocks (Baird, Friedman, \& Schady, 2011). At the same time, the opportunity cost of time allocated to the production of children's health may decrease with economic contractions. In this regard, Miller and Urdinola (2010) show that when Colombia's coffee trade suddenly booms, mortality rates among children increase in coffee-producing counties. These authors find evidence that when coffee prices go up, parents work more and spend less time in producing children's health.

While previous work has emphasized the role of credit constraints and time allocations in the relationship between economic fluctuations and children's health, it has remained silent on the interaction between behavioral responses and biological constraints. This is somewhat surprising in light of the empirical evidence suggesting the existence of critical periods (during gestation) for children's health (in particular birth outcomes) and calls for a better understanding of how macroeconomic shocks affect maternal, and subsequently fetal health, during gestation. When households experience a (negative) income shock at a critical period for children's health, they may react by substituting consumption of nutritious food from a noncritical period to a critical one as long as they are not credit constrained. If the shock happens instead during a noncritical period, households may not need to update their allocation of resources.

The goal of this paper is not only to study the impact of economic crises on children's health, but to investigate the importance of biological constraints in shaping behavioral responses. To this end, we focus on birth weight, which is mainly a function of the length of gestation (GL) and the intrauterine growth (IUG) of the fetus (Kramer, 1987). While IUG depends on maternal nutrition, maternal stress appears to be the most important determinant of GL. During bad times, food security is threatened, and individuals suffer from psychosocial stress. In addition, deep recessions can lead to dramatic losses of resources, to the extent that credit-constrained people may be forced to reduce their food expenditures below poverty levels. Hence, there are (at least) two plausible channels whereby exposure to a macroeconomic shock could affect birth weight: nutritional deficits and maternal (psychosocial) stress, with their impact varying according to stage of gestation. Indeed, there is evidence that birth weight is generally most responsive to nutritional changes affecting the third trimester of pregnancy, with evidence ranging from the Dutch famine (Stein \& Lumey, 2000) to the food stamp program in the United States (Almond, Hoynes, \& Schanzenbach, 2011), while maternal 
stress appears to affect birth weight when it occurs during the first trimester of pregnancy (Camacho, 2008; Torche, 2011).

We investigate the effects of the Argentine macroeconomic episode of 2001 to 2002 on birth weight and the channels through which these effects emerge. Argentina was shaken by a traumatic financial crisis at the turn of the century; its output (economic activity indicator) declined from 112 to 100 (its level in 1993) between 2001 and 2002, with economic activity in 2002 deviating $11 \%$ below its secular trend. The crisis started after mid-2001, and at the peak of the crisis, in April 2002, one out of four Argentines could not afford to buy basic foodstuffs and nearly two out of three were categorized as urban poor (under the urban poverty line). ${ }^{1}$ The occurrence of this Argentine macroeconomic episode, combined with the existence of the national registry of live births, offers the possibility of studying the effect of such a crisis on the weight of newborns by means of administrative data on more than 4 million live births that occurred over the six-year period 2000 through 2005.

Measuring economic fluctuations during pregnancy as the mean of the monthly cyclical (business cycle deviation with respect to secular trend) component of the economic activity indicator during the period of gestation (one to nine months before birth), we find that average birth weight (the prevalence of low birth weight) is procyclical (countercyclical) with respect to economic activity during pregnancy: A negative deviation of $0.1 \mathrm{log}$ units (about 11\%) from the long-term trend in economic activity during the gestational period would explain a reduction in average birth weight (increase in the prevalence of low birth weight) of about 34 to 35 grams (respectively 0.007 percentage points), depending on the empirical specification. In addition, we document that the statistically relevant periods of pregnancy are the first and third trimesters and seek to understand the channels behind the birth weight procyclicality with respect to these trimesters.

After stratifying the sample by mother's education (our socioeconomic status indicator), our data reveal that economic fluctuations during both the first and the third trimesters of pregnancy matter for low-educated (less than high school) mothers, while for high-educated (high school or above) mothers, only economic fluctuations during the first trimester are relevant. This is consistent with nutritional deficiencies affecting low-educated mothers, who are more likely to be credit constrained, while stress associated with economic downturns affects both low- and high-educated mothers. Our results are robust to controlling for several observable characteristics (mother's age, birth order, mother's marital status), and both region-specific month of birth fixed effects

\footnotetext{
1 Technically, these were individuals who lived in households whose tota income was below a basic-foodstuffs basket (canasta básica alimentaria) that covers the minimal nutritional requirements for an individual of a certain sex and age. Further information can be found in an online report prepared by Argentina's National Institute of Statistics and Censuses (INDEC), available at http://www.indec.mecon.ar/nuevaweb/cuadros /74/pobreza2.pdf.
}

and region-specific year of birth fixed effects. In addition, our empirical strategy is reinforced by the fact that postnatal economic fluctuations (one to nine months after birth) are not related to birth weight (or the prevalence of low birth weight).

To account for selection into pregnancy based on unobservable characteristics, we make use of an event within the period under analysis: the economic collapse of 2002. In light of the evolution of both economic activity and consumer confidence indicators, the collapse was very unlikely to be anticipated by mothers who decided to become pregnant before August 2001. Within this group, some of them gave birth to babies who were exposed in utero to the collapse, while the rest gave birth to babies who were not exposed in utero to the collapse. Using month-by-month average-birth-weight comparisons between years, we obtain reduced-form estimates. The largest gap among babies conceived before August 2001, 36 grams, is found in April 2002: for the group of babies who were exposed in utero to the crisis from the very beginning (August 2001) to its peak (April 2002). Month-by-month deviations of average birth weight in 2000 with respect to those of 2001 indicate that the 2001-2002 mean birth weight drop was too big to reflect an underlying time trend.

Although birth weight is the most important determinant of perinatal, neonatal, and postneonatal outcomes (McCormick, 1985; Pollack \& Divon, 1992), there is limited evidence on its response to economic crises, as documented by Friedman and Sturdy (2011). The estimated 30 gram effect that we uncover for the Argentine sudden economic collapse is more than three times higher than the 8.7 gram reduction due to stressful events estimated by Camacho (2008), and more than half of the 57 gram difference explained by the intensity of a mother's smoking behavior (twenty cigarettes per day versus more than one pack per day; see Abel, 1980). While the annual aggregate statistics on both infant mortality and neonatal mortality rates display stable negative secular time trends without any sudden change in their evolution during the period of analysis, suggesting that none of them was affected by the crisis, it is important to highlight that children with low birth weight who survive into adulthood have (on average) worse outcomes in terms of educational attainment and earnings (Behrman \& Rosenzweig, 2004; Black, Devereux, \& Salvanes, 2007).

The paper is organized as follows. In section II, we present a description of the data. In section III, we report our estimates of the effect of prenatal economic fluctuations on birth weight. In section IV, we investigate the channels explaining our main results. In section $\mathrm{V}$, we present an event study to address potential endogeneity concerns of our previous estimates. Section VI concludes.

\section{Data}

\section{A. Informe Estadístico del Nacido Vivo}

The main source of data for this study is the Argentine national registry of live births, Informe Estadístico del 
trend either. Finally, the fraction of girls was stable at 0.49 during the period.

The second panel in the table contains selected economic, financial, and social indicators. The economic activity indicator declined by more than 12 points between 2001 and 2002, resulting in an economy that was $11 \%$ below its long-term trend in 2002. The increase in (urban) poverty between 2001 and 2002 was dramatic: from $38.3 \%$ to $57.5 \%$, almost a 20 percentage point increase, as a result of a combination of increased unemployment and a steep drop in real wages due to inflation pressures caused by a sharp depreciation of the national currency. ${ }^{2}$ The financial turmoil is illustrated by the explosion suffered by the interest rate spread between 2000 and 2001. The evolution of health expenditure per capita, with its drop between 2001 and 2002, highlights the importance of accounting for province-specific year fixed effects when analyzing the relationship between birth weight and prenatal economic fluctuations. ${ }^{3}$

The last panel, devoted to mother's characteristics, shows positive time trends in both age and educational attainment of mothers, reflecting the well-known global trends of female educational attainment growth and postponed fertility. There is some cyclicality in terms of the number of pregnancies and partnership status: the average number of total births per mother is higher with the economic crisis, and the fraction of mothers without a partner is lower with the crisis. ${ }^{4}$ Although the differences are statistically significant, they are small in magnitude.

Figure 1 plots the annual evolution of the index of economic activity and the average birth weight of babies born from 1997 through 2006. Two dimensions merit attention in this figure. First, the evolution of average birth weight almost mimics that of the economic activity indicator, with a sharp fall between 2001 and 2003. Second, although the crisis peaked in 2002, birth weight was at its nadir in 2003. This can be explained if birth weight is the cumulative effect of different inputs during the pregnancy period or by the existence of critical development periods (that is, critical trimesters of gestation), even if no cumulative exposure exists. Similarly, we observe that while the economy started its recovery in 2003, average birth weight started recovering one year later. By 2005 average birth weight fully recovered its precrisis level.

\section{Economic Fluctuations and Birth Weight}

Economic fluctuations are measured at the month level and defined as the deviations of the log index of economic

\footnotetext{
2 By June 2002, the value of the peso relative to the U.S. dollar was reduced to a quarter of what it had been in December 2001.

${ }^{3}$ Health expenditure per capita is defined as the sum of public and private health expenditures as a ratio of total population. It covers the provision of health services (preventive and curative), family planning activities, nutrition activities, and emergency aid designated for health but does not include provision of water and sanitation.

${ }^{4}$ There is a change in the IENV questionnaire between 2000 and 2001. This may explain the jump in partnership status between 2000 and 2001.
}

Figure 1.-AnNual Evolution of Average Birth Weight and Economic ACTIVITY, 1997-2006

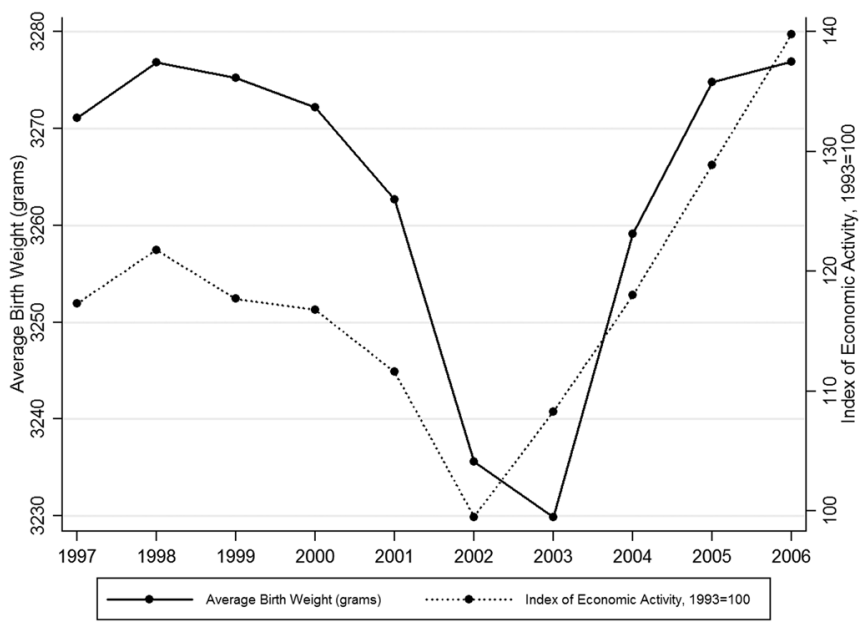

Sources: Data on average birth weight come from table 1 in Bozzoli, et al. (2012). The index of economic activity comes from INDEC: http://www.indec.mecon.ar/nuevaweb/cuadros/17/Estim-mensual -activ-econ_SH.xls.

activity with respect to its long-term trend (expressed in log units). 5 This deviation is usually referred to as the cyclical component, in that it isolates business cycle fluctuations. We denote the cyclical component in month $m$ of year $t$ by $C_{m, t}{ }^{6}$ In the case under consideration, the economy plunges into a recession so quickly that by January 2002, economic activity is more than $10 \%$ below its long-term trend.

We first link birth weight with economic fluctuations during pregnancy, estimating regressions of the form

$$
\begin{aligned}
B W_{i, r, m, t}= & \beta_{P} C_{P, m, t}+\beta_{A} C_{A, m, t}+G_{i}+I_{m}+\kappa_{r}+\tau_{t} \\
& +\rho_{r t}+\sigma_{r m}+X_{i} \Gamma+\varepsilon_{i, r, m, t},
\end{aligned}
$$

where $B W_{i, r, m, t}$ is the birth weight in grams (or a low birth weight indicator) of child $i$ whose mother's province of residence was $r$ born in month $m$ in year $t ; C_{P, m, t}$ is our measure of economic fluctuations during pregnancy (the average of the monthly cyclical component in the one to nine months before birth) for a birth that occurred in month $m$ in year $t$; and $\varepsilon_{i, r, m, t}$ is a random error term. The parameter of interest

\footnotetext{
5 We use the deviation rather than the level of economic activity since the level is likely to be more important than the deviation from its trend when thinking of the relationship between economic conditions and stress. In particular, given existing empirical research, it is natural to think of negative deviations of economic activity with respect to its secular trend as major determinants of both economic insecurity and stress. In addition, while the level may well be more important in explaining the relationship between economic activity and nutrition, deviations of economic activity are more exogenous than levels of economic activity, at least from the parents' point of view regarding the decision to have a child.

${ }^{6} C_{m, t}$ is obtained by using the Hodrick-Prescott (HP) filter, a standard decomposition method for identifying fluctuations at business cycle frequencies (i.e., booms and recessions). We apply the HP filter to the monthly log seasonally adjusted economic activity index from January 1993 through December 2006. Since we are using monthly data, we follow Ravn and Uhlig (2002) and choose a smoothing parameter of 129,600. The seasonally adjusted economic activity index, produced by the INDEC, is available at http://www.indec.mecon.ar/nuevaweb/cuadros/17/Estim-mensual-activ -econ_SH.xls.
} 
is $\beta_{P}$, which measures the sensitivity of birth weight to prenatal economic fluctuations. Our full specification includes the following list of covariates: $C_{A, m, t}$, which is a measure of postnatal economic fluctuations (the average of the monthly cyclical component during the first nine months after birth) for a birth occurring in month $m$ in year $t . \beta_{A}$ reflects the sensitivity of birth weight to postnatal economic fluctuations; $G_{i}$, a gender of child fixed effect; $I_{m}$, month of birth fixed effects, to account for seasonality patterns in birth weight; $\kappa_{r}$, mother's province of residence fixed effects, to capture regional differences in fixed prenatal infrastructure (among other fixed factors) that vary across provinces; $\tau_{t}$, year-fixed effects, to account for flexible trends in birth weight; $\rho_{r t}$ province-specific year-fixed effects, to capture omitted variables that vary simultaneously at the year and regional levels; and $\sigma_{r m}$, province-specific month-of-birth fixed effects, to capture monthly related birth weight patterns or factors that differ across regions. In addition, it also includes the set of controls $X_{i}$ : mother's age categories, birth order categories, an indicator of whether the mother has completed high school, an indicator of the mother's marital status (married or cohabiting), and the interaction of these last two variables. Regressions are estimated by OLS using clustered standard errors at the month-by-year level (72 clusters).

The estimates corresponding to various forms of regression (1) are reported in table 2 . In the first column, we run an OLS regression of birth weight on our measure of prenatal economic fluctuations controlling for month of birth, mother's province of residence, and year of birth fixed effects: the point estimate is 341.80 ( $p$ value $<0.01$ ). Birth weight is procyclical with respect to prenatal economic fluctuations. To understand the magnitude of our estimate, note that a (negative) deviation of $0.1 \mathrm{log}$ units (about 11\%) from the long-term trend in economic activity during the gestational period would explain a reduction in average birth weight of about 34 grams $(0.1 \times 341.80)$. In column 2 , we add a gender of the child indicator and mother's characteristics; the new point estimate is virtually the same. ${ }^{7}$ Looking at the rest of the coefficients, we can see that at birth, girls are on average 103 grams lighter than boys, a finding similar to that of Kramer (1987). In addition, newborns of highly educated mothers are on average 19 grams heavier than those whose mothers are not, which is consistent with previous studies linking maternal education and birth-weight outcomes (Currie, 2009).

Column 3 includes our measure of postnatal economic fluctuations. Its estimated coefficient is 23.03 , which is

\footnotetext{
7 The gender of the child is not associated with prenatal economic fluctuations. Mother's age, mother's total number of births, and mother's educational attainment are related to prenatal economic fluctuations. However, the magnitudes of the corresponding point estimates imply very small effects. A positive deviation of $0.1 \log$ units (about $11 \%$ ) from the long-term trend in the economic activity during the prenatal period would explain a decrease in average mother's age of 0.1 years, average total number of births of 0.02 births, and in the fraction of high-educated mothers of 0.004 points. Results are reported in the online appendix.
}

small in magnitude and far from being statistically significant at conventional levels. A (negative) deviation of 0.1 $\log$ units (about 11\%) from the long-term trend in the economic activity during the first nine months after birth would explain a reduction in average birth weight of about 2 grams $(0.1 \times 23.03)$. This result is reassuring, and it serves as a falsification test for our empirical strategy. While economic fluctuations during pregnancy matter for child health at birth, child health at birth is not affected by economic fluctuations after birth (as long as there are no anticipation effects). In columns 4 and 5, we include province-specific year-ofbirth fixed effects and province-specific month-of-birth fixed effects. These additional adjustments make no difference for either our point estimate of $\beta_{P}$ or its statistical significance. Finally, in columns 6 to 10, we conduct the same analysis as in columns 1 to 5 but using a low birth weight (LBW) indicator $(\leq 2,500 \mathrm{~g})$ rather than birth weight. The main message of these regressions is that LBW is countercyclical with respect to prenatal economic fluctuations: A (negative) deviation of $0.1 \log$ units (about 11\%) from the long-term trend in the economic activity during the prenatal period would explain an increase in the prevalence of LBW of 0.007 percentage points.

Since the literature on the determinants of birth weight suggests that the effects of economic shocks (fluctuations) vary according to the stages of gestation, for each birth we now create a measure of economic fluctuations in each of the three quarters that a pregnancy usually takes. For the first quarter of pregnancy, we take the average of the monthly cyclical component in those three initial months, $C_{1, m, t}$, and we do a similar procedure for the second and third quarters of pregnancy, $C_{2, m, t}$ and $C_{3, m, t} .8$

We estimate regressions of the form

$$
\begin{aligned}
B W_{i, r, m, t}= & \sum_{T=1}^{3} \gamma_{T} C_{T, m, t}+\gamma_{A} C_{A, m, t}+G_{i}+I_{m}+\kappa_{r} \\
& +\tau_{t}+\rho_{r t}+\sigma_{r m}+X_{i} \Gamma+u_{i, r, m, t},
\end{aligned}
$$

where $C_{T, m, t}$ is our measure of economic fluctuations in the trimester $T$ of pregnancy (the average of the monthly cyclical component in the trimester $T$ of pregnancy) for a birth that occurred in month $m$ in year $t$, and $u_{i, r, m, t}$ is a random error term. $\gamma_{T}$ reflects the sensitivity of birth weight to economic fluctuations during trimester $T$ of pregnancy.

Table 3 contains the estimates of various forms of regression (2). The columns follow the same strategy of table 2, including additional controls sequentially. According to the results in table 3 , it is only economic fluctuations in the first

\footnotetext{
${ }^{8}$ We define $C_{3, m, t}=\frac{1}{3} \sum_{k=1}^{3} C_{(m \times t)-k}, C_{2, m, t}=\frac{1}{3} \sum_{k=4}^{6} C_{(m \times t)-k}$, and $C_{1, m, t}=\frac{1}{3} \sum_{k=7}^{9} C_{(m \times t)-k}$, where $(m \times t) \equiv m+12 \times(t-2000)$. Babies are born from 2000 through 2005. For the group of babies born in January 2000, the cyclical component nine months before birth would be the one corresponding to $(1 \times 2000)-9=1+12 \times(2000-2000)-9=-8$ (April 1999). Our results are robust to the alternative definition: $C_{3, m, t}=\frac{1}{3} \sum_{k=0}^{2} C_{(m \times t)-k}$, $C_{2, m, t}=\frac{1}{3} \sum_{k=3}^{5} C_{(m \times t)-k}$, and $C_{1, m, t}=\frac{1}{3} \sum_{k=6}^{8} C_{(m \times t)-k}$. Results are reported in the online appendix.
} 


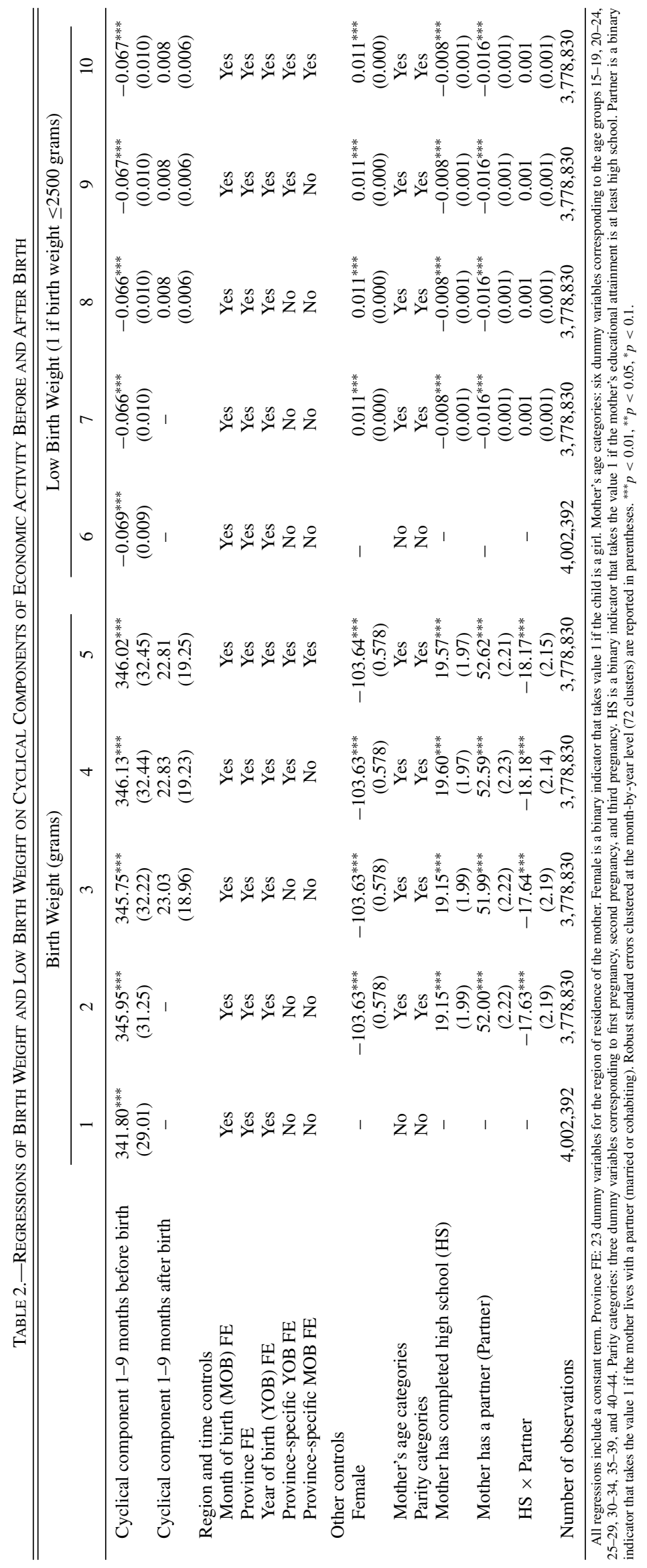




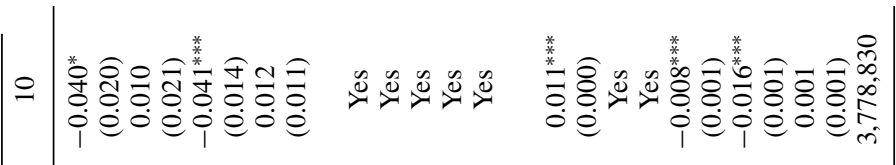

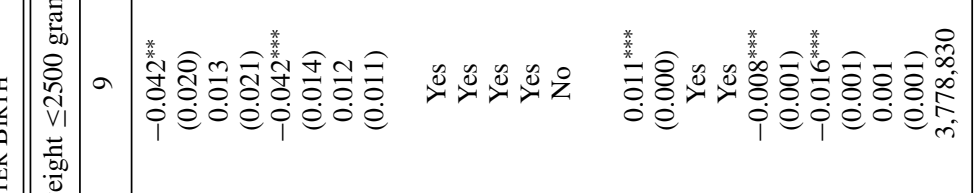

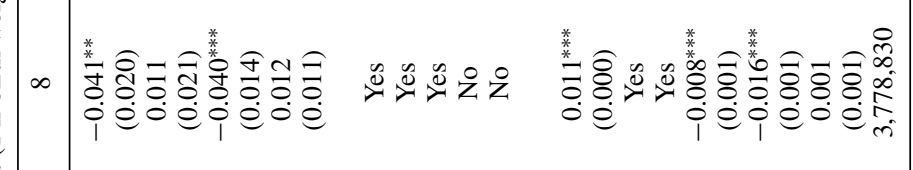

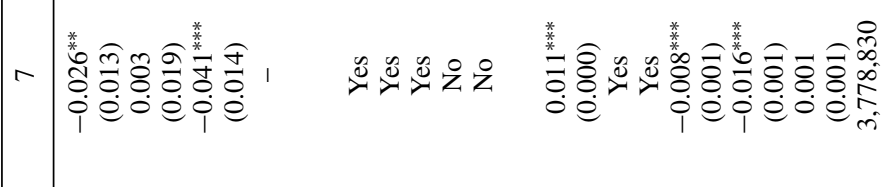

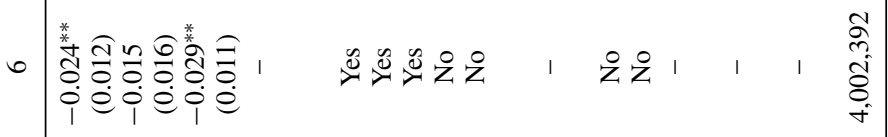

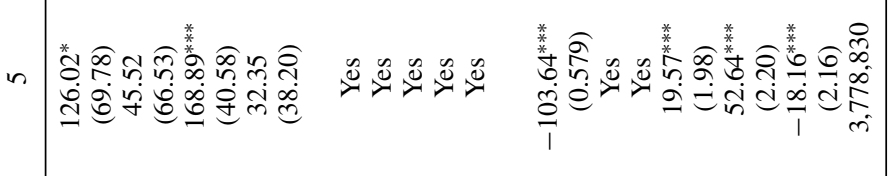

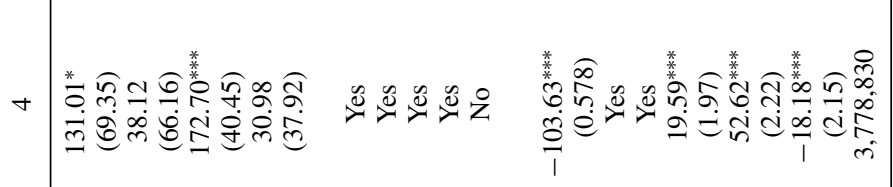

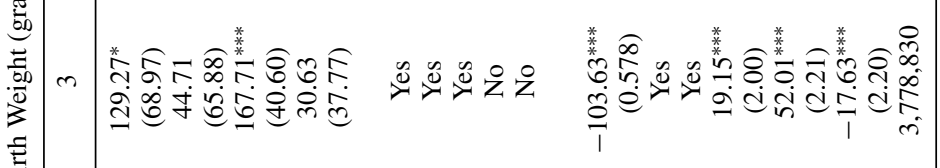

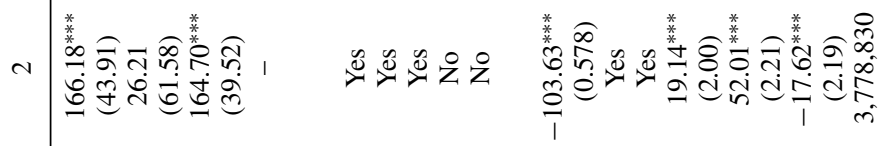

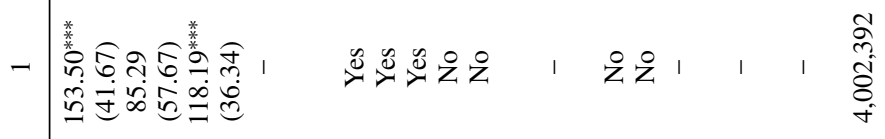

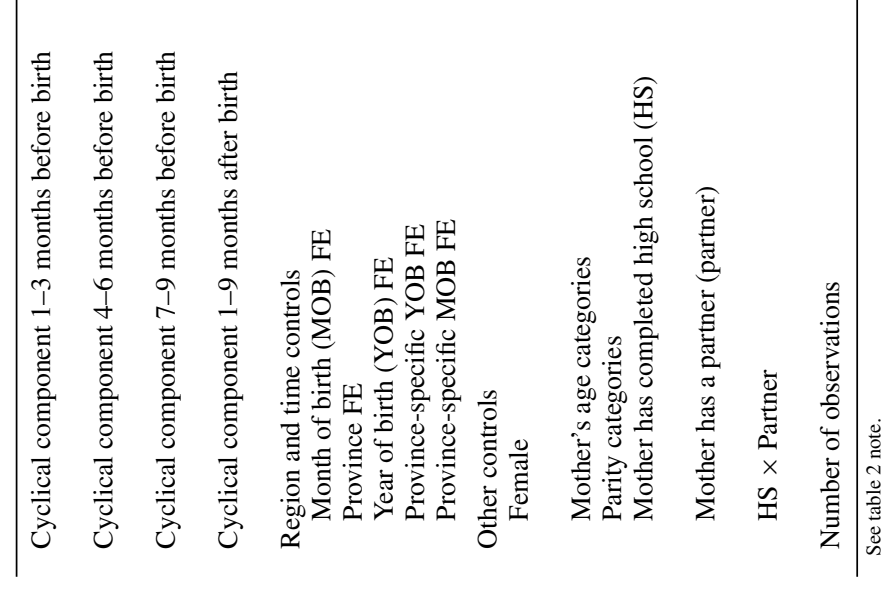


and third trimesters of pregnancy that affect birth weight (or low birth weight), consistent with the existence of critical stages of gestation. ${ }^{9}$

\section{Exploring the Channels: Nutrition or Stress?}

The results from the previous section leave an open question on the channel from negative economic fluctuations in the prenatal period to reduced average birth weight. In order to offer an answer to this question, we first review the main determinants of birth weight. To summarize Kramer (1987), birth weight can be thought of as a function of the gestation length (GL) and intrauterine growth (IUG). Maternal nutrition and cigarette smoking are the two most important and potentially modifiable determinants of IUG. While GL is more important in determining birth weight, it is also more difficult to manipulate its determinants, such as maternal stress. ${ }^{10}$

Economic crises may compromise food security and increase psychosocial stress. Dramatic reductions in resources can force credit-constrained people to reduce their food expenditures below poverty levels. Hence, there are (at least) two plausible channels whereby in utero exposure to a macroeconomic shock could affect birth weight: nutritional deficits and maternal (psychosocial) stress. More important, the impact of these determinants on birth weight varies according to the stages of gestation. In this section, we investigate the plausibility of each of these channels by exploring the sensitivity of birth weight to economic fluctuations in each trimester of pregnancy by mother's socioeconomic status (SES), that is, estimating regressions of the form (2) without including mother's education and its interaction with partnership status, by mother's SES.

\section{A. The Nutrition Channel}

The role of nutrition in affecting fetal growth (or IUG) is clear. ${ }^{11}$ If the nutritional channel is at work, a macroeconomic shock should be expected to have stronger effects on the birth weight of newborns to low-SES mothers. While high-SES mothers may be able to smooth the consumption of nutritious food during pregnancy, low-SES mothers are more likely to face credit constraints. Moreover, high-SES mothers may be

\footnotetext{
9 The correlation between the cyclical components is 0.9176 between the third and second trimesters of pregnancy, 0.7241 between the third and the first, and 0.9167 between the second and the first. Hence, it is important to keep in mind that the not statistically different from 0 correlation between birth weight and economic fluctuations in the second trimester of pregnancy can be driven by the collinearity of the second trimester with respect to the first and the third trimesters. The correlations between the prenatal and postnatal cyclical components are 0.6739 between the third and the postnatal, 0.4291 between the second and the postnatal, and 0.1866 between the first and the postnatal.

${ }_{10}$ Malnutrition may cause stress in the fetus, an important factor regarding preterm birth. See Hobel and Culhane (2003) on the role of psychosocial and nutritional stress in explaining poor pregnancy outcomes.

11 The adequacy of fetal nutrition is dependent on many factors and regulating mechanisms. These include nutrient intake of the mother, uptake of the nutrients, and fetal regulation of the nutrients.
}

able to smooth not just the consumption of nutritious food but of other critical inputs. In order to investigate the nutrition channel, we note that a woman's nutritional need varies according to the stage of gestation.

In general, birth weight is found to be most responsive to nutritional changes affecting the third trimester of pregnancy. For example, evidence from the end of World War II shows that the cohort exposed to the Dutch famine in the third trimester had lower average birth weight than cohorts exposed earlier in pregnancy (Stein \& Lumey, 2000). ${ }^{12}$ More recently, Almond et al. (2011) show that in the United States, pregnancies exposed to the food stamp program three months prior to birth yielded deliveries with increased birth weight. ${ }^{13}$ In summary, if the nutritional channel explains (part of) the loss in birth weight during the Argentine crisis, we should find that the birth weights of children born to low-SES mothers are more affected than those of high-SES mothers by economic fluctuations in the third trimester of pregnancy.

This sort of heterogeneity is analyzed in table 4 . We split the sample according to mother's educational level. Although we do not have information on family income, completion of secondary (high school) education (and above) represents a good proxy for income opportunities in Argentina (Savanti $\&$ Patrinos, 2005). We find that the sensitivity of birth weight to economic fluctuations in the third trimester of pregnancy is present only for babies born to low-educated (less than high school) mothers, which is consistent with nutritional shocks affecting low-SES women but not their high-SES (high school or above) counterparts. Our most complete specifications, column 5 for low-educated mothers and column 10 for high-educated mothers, reveal that a (negative) deviation of $0.1 \log$ units (about 11\%) from the long-term trend in economic activity during the third trimester of pregnancy would explain a reduction in average birth weight of about 18 grams $(p$ value $<0.05$ ) for low-educated mothers and of 3 grams (not statistically different from 0 ) for high-educated mothers. The results from this table suggest that the previous procyclicality of birth weight with respect to the economic fluctuations in the third trimester of pregnancy was driven by babies born to low-educated mothers.

These findings support the existence of nutritional deficits as a mediating channel in our context. While low-educated mothers, who are more likely to be credit constrained, cannot buffer expenditures on nutritious foods, high-educated mothers do not face credit constraints or suffer from nutritional deprivation. Still, it remains to be explained why birth weight is sensitive to economic fluctuations in the first trimester of pregnancy for both low- and high-SES mothers. Columns 5 and 10 indicate that a (negative) deviation of

\footnotetext{
12 During the Dutch "hunger winter" of 1944-1945, food rations were reduced to below 1,000 calories per person for seven months. The birth weight of those exposed to famine in the third trimester dropped by about 300 grams.

13 The food stamp program is the most expensive of the U.S. food and nutrition programs. Although the program is means tested, there is no additional targeting to specific populations or family types.
} 


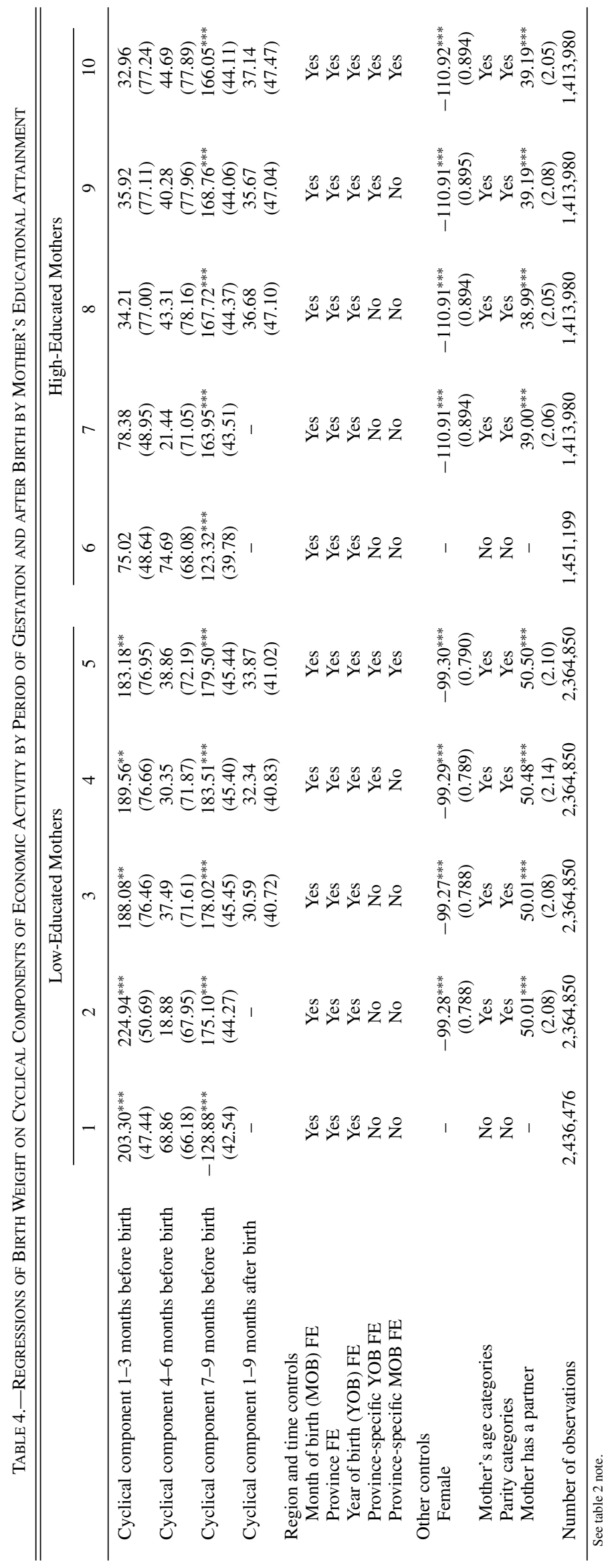


$0.1 \log$ units (about 11\%) from the long-term trend in economic activity during the first trimester of pregnancy would explain a reduction in average birth weight of about 18 grams ( $p$ value $<0.01$ ) for low-educated mothers and of 17 grams ( $p$ value $<0.01$ ) for high-educated mothers. We turn now to the stress channel to shed some light on this issue.

\section{B. The Stress Channel}

Stressful events are linked to pregnancy outcomes. Although the exact mechanism of onset of preterm labor is not known, there is growing evidence of an interaction or interplay of neuroendocrine and immunological processes (Wadhwa, Sandman, \& Garite, 2001). Stress experienced by the individual plays a role in altering both processes..$^{14}$ Perhaps more interesting is the evidence showing that birth weight is most responsive to stressful events affecting the first trimester of pregnancy (Camacho, 2008; Torche, 2011). Camacho found that in Colombia, the intensity of random land-mine explosions during a woman's first trimester of pregnancy has a negative significant impact on her child's birth weight. More recently, Torche (2011) showed that in Chile, infants exposed to a major earthquake (a source of acute maternal stress) in the first trimester of gestation had significantly lower birth weight than those unexposed or exposed later in the pregnancy.

Whether a macroeconomic shock is expected to be more stressful for low-SES than high-SES mothers is hard to know ex ante. On the one hand, high-SES mothers may have more coping mechanisms than low-SES mothers. For example, high-SES mothers have better access to counseling services, which is widespread in Argentina, a country with an exceedingly high ratio of psychologists per 100,000 (WHO, 2005). Moreover, not surprisingly, unemployment rates in May 2002 were higher for both low-SES men and women. On the other hand, in Argentina, high-SES families were particularly exposed to the freezing of deposits in banks (whose value diminished in real terms due to a large devaluation). They also may suffer from higher initial costs of adaptation to a crisis situation. As Friedman and Sturdy (2011) highlighted, the emerging evidence suggests that negative (or positive) life shocks are linked to worse (or improved) psychosocial health among adults in developing countries (Stillman, McKenzie, \& Gibson, 2009), which indicates that transitions into poverty and the conditions associated with transition are linked to an increased likelihood of poor mental health (rather than poverty per se). The estimates in table 4 reveal that economic fluctuations in the first trimester of

\footnotetext{
14 The biological pathways linking psychosocial stressors and birth outcomes have not been completely elucidated. However, a neuropeptide (corticotrophin-releasing hormone) involved in stress response and affecting the initiation of labor is thought to be a central factor. Aizer, Stroud, and Buka (2009) find that in utero exposure to elevated levels of the stress hormone cortisol negatively affects the cognition, health, and educational attainment of offspring.
}

pregnancy are associated with lower birth weight for both low- and high-SES mothers. ${ }^{15}$

Finally, we conclude with an important remark. Not only mothers of low socioeconomic status had on average lighter babies than did the others (around 19 grams according to tables 2 and 3), but less-educated mothers were hit harder by the crisis (table 4). The total birth weight loss associated with an $11 \%$ negative deviation from the long-term trend in economic activity during the first and third trimesters of pregnancy would be (adding up the corresponding coefficients) around 36 grams for children born to low-educated mothers and 20 grams for those born to high-educated mothers. In other words, babies born into poor families have a disadvantage in normal times (without recessions) which becomes even wider in bad times (with recessions).

\section{An Event Study to Measure the Weight of the Crisis}

Our previously estimated associations between birth weight and economic fluctuations in the first and third trimesters of pregnancy can be explained by (at least) two different reasons. First, it is possible that a child born to a woman of given characteristics is more likely to suffer low birth weight if economic circumstances are unfavorable. Indeed, we have already shown that birth weight is positively related to economic fluctuations in the third trimester of pregnancy for low-educated mothers but not for their high-educated counterparts. Second, it may also be the case that the composition of pregnant women (and women giving birth) changes with economic circumstances. ${ }^{16}$ In our previous analysis, we adjusted for compositional changes, including several observable mother characteristics. ${ }^{17}$ However, this does not rule out the possibility that pregnant women in periods of crisis have different unobservable characteristics than pregnant women in normal times. ${ }^{18}$

In this section, we use month-by-month variation in the timing of the crisis to exploit the fact that the extent of the Argentine crisis could not be anticipated for a group of mothers. Within this group, some of them gave birth to babies who

\footnotetext{
${ }^{15}$ Maternal psychosocial stress is negatively associated with length of gestation. We have investigated the stress channel by examining the effects of economic fluctuations on length of gestation. Our findings revealed that length of gestation is a procyclical variable with respect to prenatal economic fluctuations. Results available on request.

${ }^{16}$ Fertility decisions are likely to be affected by economic conditions, and heterogeneous mothers are likely to react differently to the crisis. See Dehejia and Lleras-Muney (2004)

${ }^{17}$ It must be noted that even when the full set of characteristics is available, compositional changes can create problems if there are interactions and other sources of nonlinearities.

18 Abortion is a potential issue here. Unfortunately, abortion data are scant, and the issue is complicated by the fact that abortion is illegal in Argentina. A study by Mario and Pantelides (2009) estimates the number of annual abortions by means of various indirect methods, adequate for describing general trends but not for projecting the evolution of abortion cases from year to year. Very crude and indirect indicators of abortion prevalence are the number of maternal deaths due to pregnancy terminating in abortion and the number of fetal deaths. These indicators have many shortcomings, and no discernible trend can be established by means of data from the Official Statistical Yearbooks (Ministerio de Salud, 2000-2009).
} 
were exposed to crisis while in utero, and the rest gave birth to babies who were not exposed. This comparison allows us to have an alternative estimate of the weight of the crisis.

\section{A. Identification Strategy}

The first step in our identification strategy relies on finding a cohort of newborns who were conceived during a period when the extent of the crisis could not be anticipated. After the crisis of 1999, the Argentine economy entered into a plateau or growth slowdown in 2000 that was sustained until mid-2001. In light of the evolution of both the economic activity and the consumer confidence indicators, as depicted in figure 2, the extent of the crisis, with the collapse of 2002, was not likely to be anticipated before August 2001. The figure shows that the deviation of economic activity with respect to its long-term trend became negative in August 2001 and from there went down to the collapse of 2002. In addition, it also reveals that the consumer confidence index dropped sharply after August 2001.19 Perhaps more interesting (although not reported here) is the fact that this drop is of the same magnitude whether the consumers in question are of low or high socioeconomic status. ${ }^{20}$ Hence, although mildly pessimistic expectations may have prevailed throughout the period, it is reasonable to assume that (the extent of) the crisis could not be anticipated before August 2001.

By using information on births occurring from 2000 through 2005, we can distinguish three groups of births according to their exposure and anticipation of the crisis: (a) pretreatment group (babies both conceived and born before the onset of the crisis in August 2001), (b) unanticipated treatment group (babies conceived before August 2001 and born from August 2001 to April 2002), and (c) anticipated treatment and posttreatment group (babies conceived after August 2001 and born after April 2002).

\section{B. Estimation and Results}

In order to account for seasonality patterns in birth weight, we compare monthly average birth weights in 2000, 2002, 2003, 2004, and 2005 with those of 2001 (reference year). Means of birth weight by month are estimated as the coefficients of the following model,

\footnotetext{
${ }^{19}$ Cárdenas and Henao (2010) compute an index (LACER) combining real, financial, and confidence variables, using principal component analysis, which shows the same sort of jump by mid-2001.

20 The Consumer Confidence Index, available from March 2001 at the national level and elaborated by the Centro de Investigación y Finanzas (CIF) of Universidad Torcuato Di Tella, is based on a monthly survey of consumer expectations similar to surveys used in OECD countries (http://www .utdt.edu/download.php?fname $=$ 133036398737682600.xls). We thank the CIF of Universidad Torcuato Di Tella, and especially Guido Sandleris, Ernesto Schargrodsky, and Julieta Serna, for providing us with the access that we needed in order to disaggregate consumer-confidence indicators by socioeconomic status. However, due to confidentiality reasons, the disaggregated indicators cannot be reported.
}

FiguRE 2.-MONTHLY EVOLUTION OF ECONOMIC ACTIVITY AND CONSUMER CONFIDENCE, 2000-2002

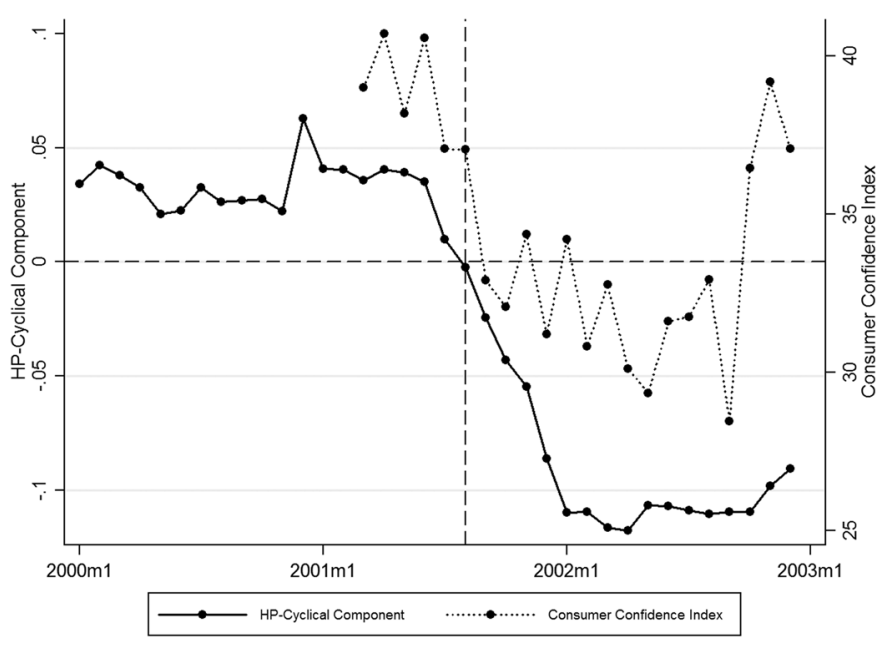

Sources: We constructed the HP cyclical component by applying the HP filter to the monthly log seasonally adjusted economic activity index from January 1993 through December 2006. The seasonally adjusted economic activity index comes from INDEC:http://www.indec.mecon.ar/nuevaweb/cuadros/17 /Estim-mensual-activ-econ_SH.xls. The Consumer Confidence Index is available from March 2001 at the national level and elaborated by the Centro de Investigacin y Finanzas of Universidad Torcuato di Tella: http://www.utdt.edu/download.php?fname=_133036398737682600.xls.

$$
\begin{aligned}
B W_{i, r, m, t}= & \sum_{m=1}^{12} \delta_{m} I_{m}+\sum_{m=1}^{12} \sum_{t \neq 2001}^{2005} \theta_{m, t} I_{m} Y_{t}+G_{i}+\kappa_{r} \\
& +X_{i} \Gamma+v_{i, r, m, t}
\end{aligned}
$$

where $G_{i}=1$ if the gender of the child $i$ is female, $I_{m}=1$ if the month of birth is $m, Y_{t}=1$ if the year of birth is $t, \kappa_{r}=1$ if the mother's province of residence is $r, X_{i}$ is defined as before, and $v_{i, r, m, t}$ is a random error term. $\delta_{m}$ is the adjusted average birth weight in month $m$ of year 2001, while $\theta_{m, t}$ is the adjusted difference in average birth weight between $t$ and 2001 in month $m$.

Importantly, the interpretation of $\theta_{m, t}$ depends on $m$ and $t$. If $t=2000$ and $m \geq 8$ or $t=2002$ and $m<5, \theta_{m, t}$ captures unanticipated treatment effects of the economic crisis as the differences in average birth weight between 2000 and 2001 by month (from August through December) and as the differences in average birth weight between 2002 and 2001 by month (from January to April). Note that since 2001 is the year of reference, $\theta_{m \geq 8,2000}>0$ and $\theta_{m<5,2002}<0$ would be interpreted as reductions in average birth weight due to the crisis. The identification strategy requires that there are no month-of-birth-specific time trends in average birth weight. Reassuringly, figure 1 indicates that the 2001-2002 difference in average birth weight documented in table 1 (27 grams) exceeds any underlying downward trend in the data. If $t \geq 2002$ and $m \geq 5$, the effects of the economic crisis (and the subsequent recovery) are potentially confounded with the effect of selection into pregnancy (or fertility postponement) of mothers who already knew (or anticipated) the extent of the crisis (with the collapse of 2002). Hence, in that case, $\theta_{m, t}$ captures both anticipated treatment effects and posttreatment 


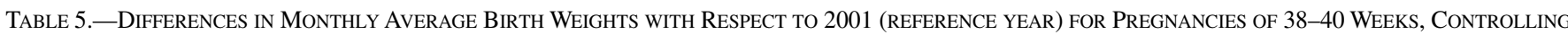
FOR MOTHERS' CHARACTERISTICS

\begin{tabular}{|c|c|c|c|c|c|c|}
\hline & 2000 & 2001 & 2002 & 2003 & 2004 & 2005 \\
\hline January & $4.5^{* * *}$ & $3,405.7$ & $-15.9^{* * *}$ & $-26.4^{* * *}$ & $-6.1^{* * *}$ & $10.6^{* * *}$ \\
\hline February & $0.7^{* * *}$ & $3,413.5$ & $-17.9^{* * *}$ & $-30.5^{* * *}$ & $-11.9^{* * *}$ & $15.4^{* * *}$ \\
\hline March & $12.5^{* * *}$ & $3,409.7$ & $-26.2^{* * *}$ & $-27.7^{* * *}$ & $-5.9^{* * *}$ & $18.8^{* * *}$ \\
\hline April & $11.4^{* * *}$ & $3,412.4$ & $-36.0^{* * *}$ & $-24.9^{* * *}$ & $-1.9^{* * *}$ & $21.8^{* * *}$ \\
\hline May & $8.9^{* * *}$ & $3,416.8$ & $-40.1^{* * *}$ & $-28.9^{* * *}$ & $-1.3^{* * *}$ & $19.2^{* * *}$ \\
\hline June & $9.0^{* * *}$ & $3,413.8$ & $-36.6^{* * *}$ & $-26.7^{* * *}$ & $0.4^{* * *}$ & $23.3^{* * *}$ \\
\hline July & $-0.6^{* * *}$ & $3,414.0$ & $-45.3^{* * *}$ & $-27.9^{* * *}$ & $3.6^{* * *}$ & $18.8^{* * *}$ \\
\hline August & $-1.5^{* * *}$ & $3,415.4$ & $-40.0^{* * *}$ & $-25.7^{* * *}$ & $9.2^{* * *}$ & $25.8^{* * *}$ \\
\hline September & $\mathbf{6 . 2} \mathbf{2}^{* * *}$ & $3,419.2$ & $-44.1^{* * *}$ & $-17.9^{* * *}$ & $11.4^{* * *}$ & $28.8^{* * *}$ \\
\hline October & $8.7^{* * *}$ & $3,414.6$ & $-40.6^{* * *}$ & $-9.7^{* * *}$ & $16.8^{* * *}$ & $29.8^{* * *}$ \\
\hline November & $15.2^{* * *}$ & $3,408.7$ & $-37.2^{* * *}$ & $-10.3^{* * *}$ & $24.2^{* * *}$ & $32.1^{* * *}$ \\
\hline December & $26.0^{* * *}$ & $3,397.0$ & $-26.0^{* * *}$ & $-4.7^{* * *}$ & $29.1^{* * *}$ & $31.1^{* * *}$ \\
\hline Mean & $8.4^{* * *}$ & $3,411.7$ & $-33.8^{* * *}$ & $-21.8^{* * *}$ & $5.6^{* * *}$ & $23.0^{* * *}$ \\
\hline
\end{tabular}

The total number of observations is 2,860,246. The reported coefficients are estimated from equation (3). The second column (2001) reports the estimates of $\delta_{m}$ controlling for year-specific month of birth fixed effects plus the previous controls: female, mother's age categories, parity categories, mother's education, mother has a partner, and the interaction of mother's education with mother has a partner. The rest of the columns $\left(2000,2002,2003,2004\right.$, and 2005) report the estimates of $\theta_{m, t} \cdot p$-values based on robust standard errors are clustered at the month-by-year level (72 clusters). Unanticipated treatment effects are in bold, and anticipated treatment and posttreatment effects in italics. ${ }^{* * *} p<0.01, * * p<0.05,{ }^{*} p<0.1$.

effects. Finally, if $t=2000$ and $m<8, \theta_{m, t}$ captures pretreatment effects by comparing average birth weight between 2000 and 2001 by month from January to August. In principle, if the crisis was unanticipated before August 2001, we should not find pretreatment effects.

Table 5 displays the monthly mean birth weight in 2001 (column 2) and the monthly differences in average birth weight of 2000, 2002, 2003, 2004, and 2005 with respect to 2001 (reference year). Our main focus is on estimated unanticipated treatment effects, which are highlighted in bold. Pretreatment effects are reported in normal font, while anticipated treatment and posttreatment effects are displayed in italics. Not surprisingly, the estimated (unanticipated) treatment effects range from a negligible 1.5 grams for those born in August 2001, who were exposed to the beginning of the crisis during at most the last month of pregnancy, to -36 grams for those born in April 2002, who were exposed to the economic crisis during all trimesters of pregnancy from its low intensity (in economic terms) in August 2001 (economic activity was $0.2 \%$ below its long-term trend) to its peak in April 2002 (economic activity was $11 \%$ below its long-term trend). Estimated posttreatment and anticipated treatment effects range from -45 grams for those born in July 2002 to 32.1 for those born in November 2005. Finally, estimated pretreatment effects are small. The mean of the monthly differences in average birth weight between 2000 and 2001 from January to July is 6.6 grams. This magnitude is roughly half of the 11 grams mean reduction for those born from August to December 2001 and one-fourth of the 24 grams for those born from January to April 2002. The bottom row of the table displays the evolution of adjusted average birth weight over the period 2000 to 2005: its drop of 33.8 grams between 2001 and 2002 and its recovery after 2003.21

\footnotetext{
${ }^{21}$ Similar qualitative results are obtained without either controlling for mothers' characteristics or restricting our sample to births with 38 to 40 weeks of gestation. Results are reported in the online appendix.
}

\section{Conclusion}

The occurrence of the Argentine macroeconomic collapse in 2001-2002, combined with the existence of administrative data on more than 4 million live births that occurred over a six-year period, from 2000 through 2005, has allowed us to investigate the effects of economic crises on an important child health metric, birth weight. We have shown that birth weight is procyclical with respect to the first and third trimesters of pregnancy. However, splitting our sample by mother's socioeconomic status, we uncover that economic fluctuations during both the first and the third trimesters of pregnancy matter for low-educated (less than high school) mothers, while for high-educated (high school or above) mothers, only economic fluctuations during the first trimester are relevant. This is consistent with nutritional deficiencies affecting low-educated mothers, who are more likely to be credit constrained, while stress associated with the negative economic fluctuations affects both low- and high-educated mothers.

To address endogeneity concerns, we perform an event study analysis. In light of the evolution of both the economic activity and the consumer confidence indicators in Argentina, the extent of the crisis could not be anticipated before August 2001, even though mildly pessimistic expectations may have prevailed throughout the period. The results from the event study, with an estimated loss in average birth weight of around 30 grams, are consistent with our previous estimates on the relationship between birth weight and economic fluctuations by trimester of pregnancy. The average birth weight loss due to the Argentine crisis is more than three times higher than the 8.7 gram reduction due to stressful events estimated by Camacho (2008) and more than half of the 57 gram difference explained by the intensity of a mother's smoking behavior (Abel, 1980).

The results of this paper contribute to our understanding of the impact of economic crises on child health and complement an emerging body of evidence showing that both 
maternal nutrition late in pregnancy (Almond et al., 2011) and stress early in pregnancy (Torche, 2011) affect birth outcomes. Generalizing results based on the stress induced by the freezing of deposits (including a 70\% depreciation of its value in dollars) to other types of stress is a challenging task. As Torche (2011) recently emphasized, the response to different types of stressors, depending on duration (chronic versus temporary) and intensity, may be quite complex. Only the accumulation of evidence on different types of stressors in different contexts will allow us to elucidate the exact role of socioeconomic stressors in explaining birth outcomes.

Our findings are striking because the reduction in average birth weight occurred in a middle- to high-income country with a physician-to-patient ratio similar to those of Germany and Norway, affecting both low- and high-educated mothers. Although it is too early to have any longer-term follow-up outcomes (for example, educational attainment or earnings later in life for the affected cohorts versus those in utero just before), the price paid will be higher for some than for others, since birth weight of children born to low-educated mothers is more sensitive to economic shocks. This discrepancy may exacerbate income inequalities in the long run.

There are certain limitations of this study that must be acknowledged. Probably the most important one is the absence of information on direct measures of maternal nutrition and stress, which should be taken into account in the design of future data collection schemes. However, our findings represent an advance in understanding the impact of economic crises, and more generally macroeconomic activity, on children's health, after accounting for the interactions between biological channels, timing of (economic) insults, and household behavioral responses.

\section{REFERENCES}

Abel, Ernest L., "Smoking during Pregnancy: A Review of Effects on Growth and Development of Offspring," Human Biology 52:4 (1980), 593-625.

Aizer, Anna, Laura Stroud, and Stephen Buka, "Maternal Stress and Child Well-Being: Evidence from Siblings," mimeograph, Brown University (2009)

Almond, Douglas, Hilary W. Hoynes, and Diane Whitmore Schanzenbach, "Inside the War on Poverty: The Impact of Food Stamps on Birth Outcomes," this REVIEW 93:2 (2011), 387-403.

Baird, Sarah, Jed Friedman, and Norbert Schady, "Aggregate Income Shocks and Infant Mortality in the Developing World," this REVIEW 93:3 (2011), 847-856.

Behrman, Jere R., and Mark R. Rosenzweig, "Returns to Birthweight," this REVIEW 86:2 (2004), 586-601.

Bhalotra, Sonia, "Fatal Fluctuations? Cyclicality in Infant Mortality in India," Journal of Development Economics 93:1 (2010), 7-19.

Black, Sandra E., Paul J. Devereux, and Kjell Salvanes, "From the Cradle to the Labor Market? The Effect of Birth Weight on Adult Outcomes," Ouarterly Journal of Economics 122:1 (2007), 409-439.

Bozzoli, Carlos, Climent Quintana-Domeque, and Federico Todeschini, "La Evolución del Peso al Nacer en Argentina durante el Período 19972009," mimeograph, Universitat d'Alacant (2012).

Camacho, Adriana, "Stress and Birth Weight: Evidence from Terrorist Attacks," Papers and Proceedings of the American Economic Review 98:2 (2008), 511-515.
Cárdenas, Mauricio, and Camila Henao, "Latin America and the Caribbean's Economic Recovery" (Washington, DC: Brookings Institution, 2010).

Currie, Janet, "Healthy, Wealthy, and Wise: Socioeconomic Status, Poor Health in Childhood, and Human Capital Development," Journal of Economic Literature 47:1 (2009), 87-122.

Cutler, David M., Felicia Knaul, Rafael Lozano, Oscar Mendez, and Beatriz Zurita, "Financial Crisis, Health Outcomes, and Ageing: Mexico in the 1980s and 1990s," Journal of Public Economics 84:2 (2002), 279-303.

Dehejia, Rajeev, and Adriana Lleras-Muney, "Booms, Busts and Babies' Health," Quarterly Journal of Economics 119:3 (2004), 1091-1130.

Friedman, Jed, and Jennifer Sturdy, "The Influence of Economic Crisis on Early Childhood Development: A Review of Pathways and Measured Impact," in Harold Alderman, ed., No Small Matter: The Impact of Poverty, Shocks, and Human Capital Investments in Early Childhood Development (Washington, DC: World Bank, 2011).

Hobel, Calvin, and Jennifer Culhane, "Role of Psychosocial and Nutritional Stress on Poor Pregnancy Outcomes," Journal of Nutrition 133:5 (2003), 1709S-1717S.

Kramer, Michael S., "Determinants of Low Birth Weight: Methodological Assessment and Meta-Analysis," Bulletin of the World Health Organization 65:5 (1987), 663-737.

Mario, Silvia, and Edith Alejandra Pantelides, "Estimación de la Magnitud del Aborto Inducido en la Argentina," Revista Notas de Población 87 (March 2009), 95-120.

Martin, Joyce A., Brady E. Hamilton, Paul D. Sutton, Stephanie J. Ventura, Fay Menacker, and Martha L. Munson, "Births: Final Data for 2003," National Vital Statistics Reports 54:2 (2005), 1-26.

McCormick, Marie C., "The Contribution of Low Birth Weight to Infant Mortality and Childhood Morbidity," New England Journal of Medicine 312:2 (1985), 82-90.

Miller, Grant, and B. Piedad Urdinola, "Cyclicality, Mortality, and the Value of Time: The Case of Coffee Price Fluctuations and Child Survival in Colombia," Journal of Political Economy 118:1 (2010), 113-155.

Ministerio de Salud, Presidencia de la Nación, Estadísticas Vitales: Información Básica (Buenos Aires: Dirección de Estadísticas e Información de Salud, 2000-2009).

Paxson, Christina, and Norbert Schady, "Child Health and Economic Crisis in Peru," World Bank Economic Review 19:2 (2005), 203-223.

Pollack, R., and M. Divon, "Intrauterine Growth Retardation: Definition, Classification, and Etiology," Clinical Obstetrics and Gynecology 35:1 (1992), 99-107.

Ravn, Morten O., and Harald Uhlig, "On Adjusting the Hodrick-Prescott Filter for the Frequency of Observations," this REVIEW 84:2 (2002), 371-376.

Savanti, Maria Paula, and Harry Anthony Patrinos, "Rising Returns to Schooling in Argentina, 1992-2002: Productivity or Credentialism?" World Bank, Policy Research working paper WPS3714 (2005).

Stein, A. D., and H. D. Lumey, "The Relationship between Maternal and Offspring Birth Weights after Maternal Prenatal Famine Exposure: The Dutch Famine Birth Cohort Study," Human Biology 72:4 (2000), 641-654.

Stillman, Steven, David McKenzie, and John Gibson, "Migration and Mental Health: Evidence from a Natural Experiment," Journal of Health Economics 28:3 (2009), 677-687.

Torche, Florencia, "The Effect of Maternal Stress on Birth Outcomes: Exploiting a Natural Experiment," Demography 48:4 (2011), 14731491.

UNDP, Human Development Report 2009: Overcoming Barriers: Human Mobility and Development (New York: Palgrave Macmillan, 2009).

Wadhwa, Pathik D., Curt A. Sandman, and Thomas J. Garite, "The Neurobiology of Stress in Human Pregnancy: Implications for Prematurity and Development of the Fetal Central Nervous System," Progress in Brain Research 133 (2001), 131-142.

WHO, Mental Health Atlas 2005 (Geneva: World Health Organization, 2005).

World Bank, World Development Report 2009: Reshaping Economic Geography (Washington, DC: World Bank, 2009). 